Vol. 7(10), pp. 183-187, December, 2015

DOI: 10.5897/IJLIS2014.0492

Article Number: 69CE02056069

ISSN 2141-2626

Copyright (C) 2015

International Journal of Library and Information

Author(s) retain the copyright of this article

Science

http://www.academicjournals.org/IJLIS

Review

\title{
Library 2.0 and the changing landscape of information services in academic librariesin Kenya
}

\author{
Penninah S. Musangi \\ Senior Librarian - Karatina University, Kenya \\ Received 14August, 2014; Accepted 12 October, 2015
}

\begin{abstract}
Traditional models of libraries offering information services are not working for current generation of students. Thecurrent generation of library users can be termed as'digital natives'. These digital natives have grown up in an environment surrounded by rapidly evolving technologies. This means that today's academic library users think about technology and information differently than previous generations, and expect instant access to information. They can also be called 'netGen' users. With this kind of environment and expectations, academic libraries need to evolve by changing to offer user-oriented services and following users into their social spaces by allowing users to participate in the creation of content, keeping the users constantly updated and building services based on their feedback. To achieve this, libraries need to incorporate web 2.0 tools in the way they provide services. Some of the tools to take advantage of include creation of blogs, wikis, flickr, youtube, facebook, RSS feeds, socialbookmarks, microblogs, mashups and slideshare among others. Another obvious change noted today and especially in Kenya is the development of university campuses all over the country. For most of these campuses, one will find small rooms as libraries; with minimal resources and a few staff members. This is a challenge and library 2.0 being a combination of both physical and virtual spaces and services can offer solution to such campuses. In addition, many universities are offering distance learning and evening programmes to cater for the working class people who want to advance their careers. Do they have to come all the way to visit the library to get information for their studies? No. Library 2.0 is their way out and therefore academic libraries have to invest in these tools, in addition to off-campus access to e-resources. This paper will discuss library 2.0 as the new model of information provision to library users and especially in the academic world. The library 2.0 tools and technologies will be discussed and how they can be applied in an academic library.
\end{abstract}

Keywords: Library 2.0, Web 2.0, academic libraries, library service models, information senvices.

\section{INTRODUCTION}

S.R. Ranganathan's Fifth Principle of Library Science states that "the library is a growing organism" (Ranganathan, 2006). In today's libraries, this principle is clearly exemplified by the number of new forms of information sources and services that are being offered. The boundaries of libraries have broadened to accept these

*Corresponding author. E-mail: pmusang@gmail.com

Authors agree that this article remain permanently open access under the terms of the Creative Commons Attribution License 4.0 International License 
new sources and services into their daily operation. The resources of the libraries have grown from physical objects to virtual objects, as evidenced by change from card catalogues to online public access catalogues (OPACs), and cooperative cataloguing to social cataloguing providing an ability to comment, review and reuse due to application of Web 2.0 tools (Ram, 2011). Web 2.0 tools allow users to create, change, and publish dynamic content of all kinds. Since they create a two-way or read/write environment they are enabling librarians interact with the library users (Stephens and Collins, 2007). Casey and Savastinuk (2007) provide what they terms as the 'truth' in relation to changes being experienced in the libraries; that libraries are losing interest of their users, they no longer consistently offer the services users want and they are no longer the first place current and potential customers will look for information. They advise that, for a library to keep its current and reach potential users, library 2.0 is one avenue. Most academic libraries in Kenya have hinted to this advice and have not been left behind in this transformation, hence adoption of web 2.0 tools in their service provision.

\section{Library service models}

Kwanya et al. (2011) state that library service models can beperceived as types of library services which are differentiated through unique characterization such as type of collection held, target users, type of library (academic, research, school or public) in which it is offered, special features of the services offered, service philosophy, and general library organization. For a long time, academic libraries have offered information services using the traditional model of libraries being repositories of information and librarians being passive intermediaries in its transfer and interpretation. Then they moved to what is termed as 'hybrid' library model. This is where the traditional model runs parallel with digital model meaning offering services and providing information sources in both print and e-formats. This is the most common scenario in most academic libraries in Kenya today. However, this is not working well with the present generation of students. Robinson(2008) describes the current generation of undergraduate and graduate students as being digital natives. He adds that, these digital natives have grown up in an environment surrounded by rapidly evolving technologies. Therefore this means that today's academic library users think about technology and information differently than previous generations, and expect instantaccess to information which can offered through a digital library model. A digital library is a collection of services that are closely modeled on the traditional print library, but the information and the tools used to find the same is in electronic format.Since most academic libraries in Kenya cannot afford adigital library model, they have opted to revamp their hybrid models with the inclusion of web 2.0 in information provision, so as to cater for these digital natives. This has given rise to library 2.0 model.

\section{Library 2.0 model}

Kwanya et al. (2011) note that, library 2.0 is a model of library service whichharnesses the power of emerging information and communication technologies to create a dynamic physical and/or virtual library platform which is defined and controlled by the users and librarians and which facilitates the delivery of a superior library experience for the users: anytime and anywhere. Therefore, library 2.0 can be defined as a set of innovative technologies and services that are integrated with the library, facilitating the use of library resources and services, allowing library users to participate and keeping the librarians updated in their field (Zanin-Yost, 2010). Library 2.0 is a service philosophy that is guiding libraries in their effort to win new users while, at the same time, acknowledging that the current service offerings are insufficient and inflexible. Therefore library 2.0 can be termed as finding new ways of involving patrons by letting them contribute comments, add tags, rate library items, and get involved in other interactive and collaborative activities of the library.

Casey (2006) notes that library 2.0 sees the reality of the current user-base and says "not goodenough, we can reach more people". It seeks to do this through a threepart approach: reaching out to new users, inviting customer participation, and relying on constant change. Much of this is made possible thanks to new technologies such as web 2.0. Notess (2006) explores the importance of integrating web 2.0 tools into mainstream library and information services as it supports, promotes and extends information services to patrons or user spaces.

With this new service model, the focus in most academic libraries is changing to user-oriented services, by allowing users to participate in the creation of content, keeping the user constantly updated and building services based on users' feedback. To achieve this new model, libraries are incorporating web 2.0 tools in the way they provide services to their users. Some of these tools include creation of blogs, wikis, flickr, youtube, cluster maps, Google page translator, Google earth, facebook, Linkedln, RSS feeds, and slideshare among others.

\section{APPLICATION OF WEB 2.0 TOOLS IN INFORMATION SERVICES}

Web 2.0 encompasses several technologies and services. These are as discussed by Stephens and Collins (2007) and Casey and Sarastinuk (2007), with examples of how academic libraries in Kenya have been able to apply these 


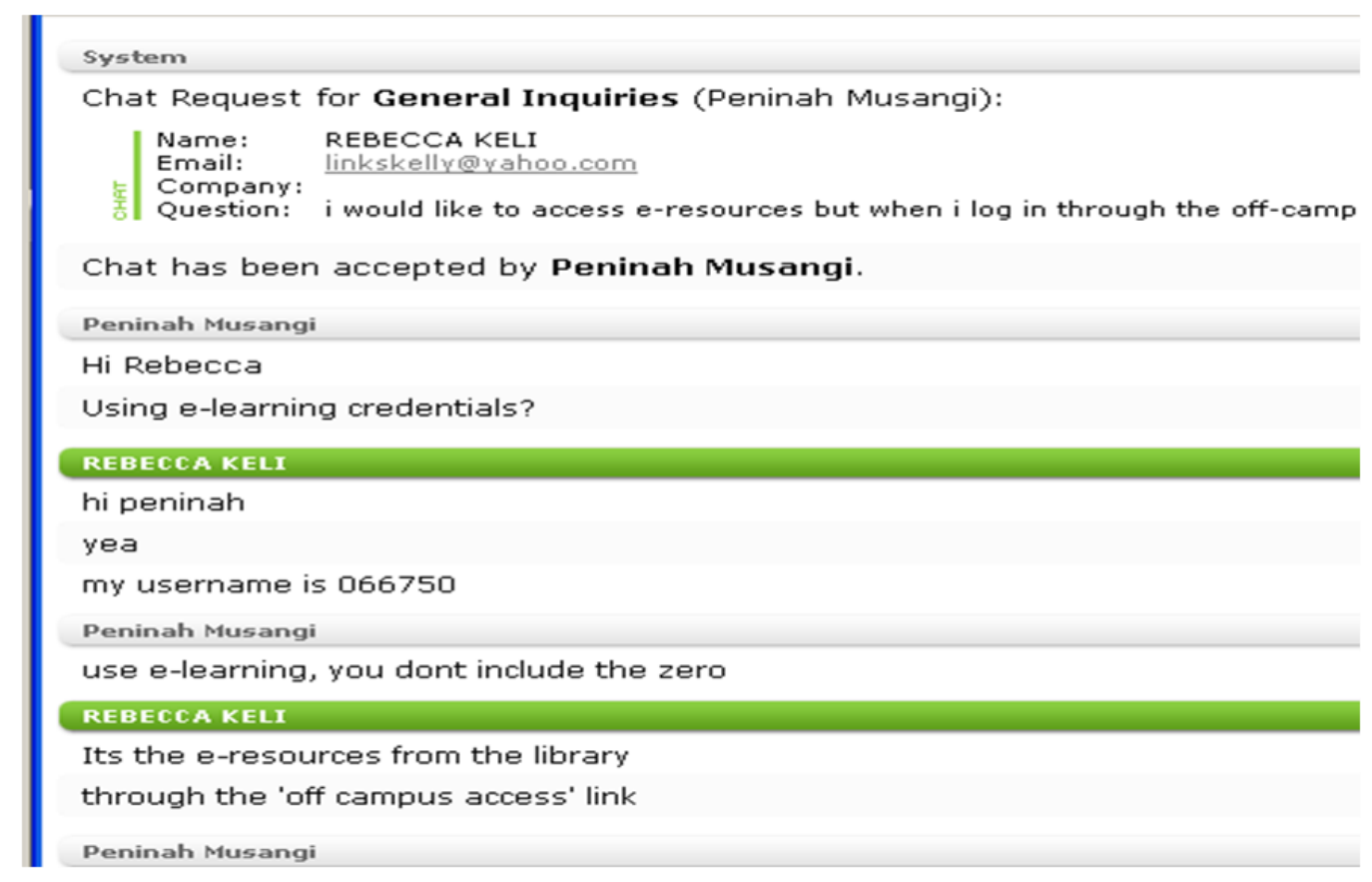

Figure 1.Instant Messaging.

technologies:

\section{Really Simple Syndication (RSS)}

This is a web feed used for syndicating content from the internet. It informs users of updates to the subscribed sites. Many web-browsers have built-in-feed readers or aggregators that easily add feeds to web page. In libraries, this has been applied to:

i. Announce the availability of new resources in a particular subject to a particularclientele.

ii. Promote events organized by the library to its users.

Integrating library services through RSS feeds. Users can be informed of any newservice a library is introducing.

Examples of RSS feed in academic libraries in Kenya; http://opac.library.strathmore.edu/cgi-bin/koha/opacsearch.pl?idx=kw\&q=financial\%20management\&count=50 \&sort_by=acqdate_dsc\&format=rss2 http://maktaba.ku.ac.ke/cgi-bin/koha/opacsearch.pl?idx=kw\&q=finance\&count=50\&sort_by=acqdate_ dsc\&format=rss2.

\section{Instant messaging (IM)}

This is real-time communication between two or more people based on typed text, or images. It is a popularmode of communication because of its quick response time, ease of use and the ability of alibrarian to multitask. Various programs are available to offer this service viz; livezilla, meeboetc. IM has been successfully implemented at Strathmore University Library whereby it is being used for:

i. Providing virtual reference services, whereby online library users can ask questions, requests and get responses instantly.

ii. Checking availability of colleagues at desks of work, instead of walking to an office and miss a colleague thereby wasting time and energy;

iii. Conducting online meetings, this does not require a member to be within campus to havethe meeting. This can be done remotely.

\section{Social networking}

Social networks enable messaging, blogging, streaming media, and tagging. MySpace and FaceBook enable users/libraries to share themselves with one another. Del.icio.us enables users to share Web resources and Flickr enables the sharing of pictures. Myspace and facebook are thetwo popular social networking sites used in academic libraries as identified through web analysis. Myspace allows organizations to create their own profiles, pages and can be used by libraries to create web pages. Facebook allows individual librarians to create profiles (Figure 1).

This has been applied in:

i. Libraries creating a page to reach to new users. Most 
academic libraries have a Facebookpage, some with Twitter pages etc.

ii. Social networks enable librarians and patrons to interact, share and change resources. This can be achieved since users can comment or suggest what resources are useful.

iii. Building network among groups to discussissues of common interest. This is through the discussion forum in the social networks which give an opportunity for groups to discuss issues affecting them.

iv. Users adding content to the library catalogue. This includes book reviews or othercomments on particular resources in regard to their usefulness or applicability to specific subjects. Since there is no single text which can sufficiently cover a whole subject at university level, commenting on a resource on where it can be used in a particular subject is good and helps to direct other users.

Examples are: https://www.facebook.com/pages/KenyattaUniversity-Library/239904162689026

https://www.facebook.com/pages/Strathmore-UniversityLibrary/152833268081020

https://twitter.com/\#!/strathlib_ke.

\section{Tagging}

A tag is a keyword added to a digital object to describe it. Tagging in a library essentially enables users to create keywords for the object at hand. As Maness (2006) describes, tagging is essentially Web 2.0 because it allows users to add and change not only content (data), but content describing content (metadata). Tagging has been extended to include social bookmarking where sites of interest, bibliographies or links to user-created content is collected and shared among the users. Academic libraries are using social bookmarking communities like delicious or Cite like. By using Flickr, users can tag pictures, while using Library Thing, they can tag books. In Library 2.0, users can tag the library's collection and thereby participate in the cataloging process and also tag items using terms relevant to such clientele. Tagging makes lateral searching easier.

Tagging has been applied in:

i. Library management systems for editing the subject headings or keywords to user point of view and thereby enhancing the indexing and relevancy of the searches, making the collection more dynamic.

ii. Facilitating lateral searching.

\section{Blogs}

Blogs are powerful two-way based tool, whereby libraryusers enter thoughts, ideas, suggestions and comments. A blog entry may contain text, images or links to other blogs and websites. A librarian or a library user can publish a blog post easily and cheaply through a web interface, and any reader can place a comment on a blog post.

Blogs have been used in libraries:

iii. To serve as a platform for users to file their concerns, queries and suggestions regarding the services and activities of the library.

iv. For collection development where users request resources.

v. As marketing tools of the information resources.

vi. As a tool for posting minutes of meetings for necessary actions.

vii. As a discussion forum.

Examples:

http://kemulib.blogspot.com/p/e-books.html

Stephen and Collins (2007) examine the principles of web 2.0, which have made it possible for library 2.0 to be conceptualized and put in place as discussed in the preceding section. These principles include:

i. Conversation: with the use of web 2.0 tools, user participation, discussion and feedback is possible and therefore encouraged.

ii. Community: the first principle of conversation can lead to a sense of community and belonging within the social sites.

iii. Participation: with the read/write capability, users create content, ideas, and knowledge which is shared between users leading to new information being created through collaboration.

iv. Experience: when users are engaged with others as a community, it is rewarding and leads to fulfilment.

v. Sharing: users are able to post as much information about what they know and enrich other users lives.

\section{RECOMMENDATIONS}

From the literature reviewed, libraries have to evolve in one way or another so as to provide services which are in tandem with the current generation of users, otherwise users will continue by-passing the library as the primary source of information. This can be achieved by incorporating web 2.0 tools among other technologies. In addition, the library needs to;

Provide information and instructionin as many formats as possible as students are accessing information using a variety of media such as video, podcasts and vodcasts rather than through the traditional channels of reading books or newspapers. Libraries should develop tutorials, videos and upload them on the library webpages or make use of YouTube, Slideshare. This can be done for orientation, guidesto e-resources, guide to use of Library Management System (LMS), information literacy. 
Make library webpages and content "GYM-enabled" that is, optimized so that it is searchable by Google, Yahoo, Bing and other search engines. This way the library will continue to maintain its relevance to the general public. This can be done by installing 'add-ons' like LibX toolbar which enables users to search the library database like Google search.

Rather than simply have social networking sites like facebook, exploit on the everevolving features of the sites. For example, facebook in May 2007 launched a platform that allows users create applications. For instance a search features for a library catalog. This application is fairly simple for libraries to create since some of the users have willingly shared the code with others wanting to do something similar. Other features include creation of groups that facebook users can join, where messages can be send to all group members in order to advertise library programs, and services; ability to create a page that users can subscribe and get updates in their profile through news feeds. In addition to these features, the librarians can make use of the profile wall to answer questions, post items to discuss, albums to share pictures of library events and share scheduled events like workshops, training or library classes.

\section{Conclusion}

Today's library users want answers and want them now, and in the most convenient manner. Unfortunately the reality is that more than 90 percent of students whowish to find out about something, the first thing they would do, would be to search from the internet and not think about the library as an option. No one would think about asking a reference librarian or even logging onto a library website to use the inquiry service. This is the new marketplace; this is where most people live and work. Thus as libraries, we must recognize that the Internet and search engines are now the main ways in which people look for information. Therefore, rather than try to change users' habits, the library can change its approach and meet users where they are; on the Web, using the tools they enjoy using. To libraries, Web 2.0 may be nothing more than just new tools of technology, but how they are used and what they are used for will determine whether libraries can survive this new E-volution.

\section{Conflict of Interests}

The author has not declared any conflict of interests.

\section{REFERENCES}

Casey M (2006). Library Crunch: Born in the Biblioblogsphere. Retrieved August 6, 2012, from http://www.librarycrunch.com/2006/01/post 1.html

Casey M, Savastinuk L (2007). Library 2.0: A guide to participatory library services. New Jersey: Information Today.

Kwanya T, Stilwell C, Underwood PG (2011). Library 2.0 versus other library service models: A critical analysis. J. Libr. Inform. Sci. 44(3):145-162doi:10.1177/0961000611426443

Maness JM (2006). Library 2.0 Theory: Web 2.0 and its Implications for Libraries. text.Retrieved August 6, 2012, from http://www.webology.org/2006/v3n2/a25.html

Notess G (2006). The terrible twos: web 2.0, library 2.0, and more. Library, 30(3): 40.

Ram SKJPA,Kataria S (2011). Responding to user"s expectation in the library: innovative Web 2.0 applications at JUIT Library: A case study. Program: electroniclibrary and information systems, 45(4), 452-469. doi:10.1108/00330331111182120

Ranganathan SR (2006). The five laws of library science. New Delhi: Ess Ess Publication.

Robinson M (2008). Digital nature and digital nurture: libraries, learning and the digital native. Library Management, 29(1/2): 67-76. doi:10.1108/01435120810844658

Stephens M, Collins M (2007). Web 2.0, library 2.0, and the hyperlinked library. SerialsReview, 33(4): 253-256.

Zanin-Yost A (2010). Library 2.0: Blogs, Wikis, and RSS to Serve the Library. Library Philosophy and Practice (e-journal).Retrievedfrom http://digitalcommons.unl.edu/libphilprac/430 